J. Andersen (ed.), Reports on Astronomy, Vol. XXIVA, 297-298.

(c)2000 IAU. Printed in the United States of America.

\title{
DIVISION VIII: GALAXIES AND THE UNIVERSE
} (LES GALAXIES ET L'UNIVERS)

\author{
PRESIDENT: P. Shaver \\ BOARD: F. Bertola, J. Narlikar, S. Okamura, J. Peacock, A. Szalay \& \\ V. Trimble
}

\section{Commission 28: Galaxies \\ Commission 47: Cosmology}

The fields of research covered by Division VIII and its two Commissions have experienced remarkable progress over the last several years. This is due at least in part to the proliferation of major new observational facilities, and the addition of the several 8-m class telescopes presently being completed and new space facilities which will have a huge impact in the years to come. Many of the important recent scientific developments are summarized on the following pages in the reports of Commission 28 and Commission 47. These reports have been prepared in the "short" form, and are intended both to present the major scientific highlights and the most important conference proceedings and reviews for further reading.

Certainly, the large number of scientific meetings attests to the health of these fields of research, and the IAU Symposia and Colloquia comprise an important and influential component. Those that have been sponsored and/or supported by Division VIII and Commissions 28 and 47 over the three years 1998-2000 are listed below:

1998:

Symp. 190: New Views of the Magellanic Clouds

Symp. 192: The Stellar Content of Local Group Galaxies

Symp. 193: Wolf-Rayet Phenomena in Massive Stars and Starburst Galaxies

Symp. 194: Activity in Galaxies and Related Phenomena

Coll. 169: Variable and Non-Spherical Stellar Winds

Coll. 171: The Low Surface Brightness Universe

1999:

Symp. 197: Astrochemistry: From Molecular Clouds to Planetary Systems

Symp. 198: The Light Elements and their Evolution

Symp. 199: The Universe at Low Radio Frequencies

Coll. 174: Small Galaxy Groups

Coll. 176: The Impact of Large-Scale Surveys on Pulsating Star Research 2000:

Symp. 200 Formation of Binaries

Symp. 201 New Cosmological Data and the Values of the Fundamental Parameters

Symp. 204 The Extragalactic Infrared Background and its Cosmological Implications Symp. 205 Galaxies and their Constituents at the Highest Angular Resolutions

Coll. 180 Towards Models and Constants for Sub-Microarcsecond Astrometry 
It is clear from this list that topics of interest are widely spread across Division boundaries as well as Commission boundaries, highlighting the value of good communication and flexibility both within and between Divisions.

The structure of Division VIII with its two Commissions has remained unchanged and continues to function well. The total membership of Division VIII is 1154, with 773 and 479 members in Commissions 28 and 47 respectively. The individual Commissions are relatively large, but the Division is a reasonable size compared to the total IAU membership of 8220. To assure continuity and coordination, the Division VIII Board includes the present and past President and Vice President of both Commissions in the Division. The size and composition of IAU Division Boards in general has been discussed over the past year, but in the case of Division VIII it is felt that, with seven persons, the Board is both representative and a manageable size. Nevertheless, the possibility of re-structuring within the Division (new Commissions, Board membership) can always be discussed and will be raised again at the next General Assembly.

P. A. Shaver

President of the Division 